[Communication]

www.chem.pku.edu.cn/whxb

\title{
一含肉桂酸的单链Bola型两亲分子在有机溶剂中的光致二聚和聚集行为
}

\author{
阎 云 ${ }^{1}$ 郭 素 ${ }^{1}$ 熊 玮 $^{1}$ 卢 婷 ${ }^{1}$ 李子臣 ${ }^{1}$ 黄建滨 ${ }^{*}$ 付宏兰 ${ }^{2}$ \\ ( ${ }^{1}$ 北京大学化学与分子工程学院, 分子动态与稳态结构国家重点实验室; ${ }^{2}$ 北京大学生命科学学院, 北京 100871)
}

\begin{abstract}
摘要 制备了一种含肉桂酸基团的 Bola 型两亲分子 HDC(4-(10-羊基癸氧基)-10-羊基癸氧基肉桂酸酯). 第一次 观察到该分子在有机溶剂中经紫外光照发生光致二聚. 分离出来的二聚 HDC 在 $20 \%$ 的乙醇/水混合溶剂中能形 成球形的囊泡. 同时发现溶剂的介电常数大小与光致二聚过程密切相关, 介电常数的大小不仅关系到反应发生 与否, 而且直接影响到反应的速率.
\end{abstract}

关键词：Bola 型两亲分子，肉桂酸衍生物，光致二聚，聚集

中图分类号: $\mathrm{O} 647$

\section{Photodimerization and Aggregation in Organic Solution of a Single Chain Bolaamphiphilic Cinnamic Acid Derivative}

\author{
YAN, Yun ${ }^{1}$ GUO, Su ${ }^{1} \quad$ XIONG, Wei ${ }^{1} \quad$ LU, Ting ${ }^{1} \quad$ LI, Zi-Chen ${ }^{1} \quad$ HUANG, Jian-Bin ${ }^{1 *}$ FU, Hong-Lan ${ }^{2}$ \\ ('State Key Laboratory for Structural Chemistry of Unstable and Stable Species, College of Chemistry and Molecular Engineering, \\ Peking University; ${ }^{2}$ College of Life Science, Peking University, Beijing 100871, P. R. China)
}

\begin{abstract}
Single chain bolaamphiphile containing cinnamyl moiety [4-( $\omega$-hydroxydecanyloxy) ( $\omega$-hydroxydecanyl) cinnamate, abr. HDC] was designed and synthesized. The photodimerization of the HDC molecules induced by UV light was the first time realized in organic solutions. The dimerized HDC was separated and formed spherical vesicles in $20 \%$ ethanol/water mixed solvents. The solvents' dielectric constants were found to play an important role in the photodimerization process. Both the occurrence of the photodimerization reaction and the rate of the reaction were affected by the dielectric constant value of the solvents.
\end{abstract}

Keywords: Bolaamphipile, Cinnamic acid derivative, Photodimerization, Aggregation

Bolaamphiphiles are the molecules with two hydrophilic head groups connected by one or two long hydrophobic chains. For their superior membrane formation ability ${ }^{[1-2]}$ and abundant aggregation behaviors ${ }^{[3-8]}$, bolaamphiphiles have attracted great interests over the past two decades. It has been found that the aggregate morphologies formed by these bolaamphiphiles are dependent on their head group properties ${ }^{[9-15]}$. In addition, the structure of the hydrophobic chains connecting the two head groups also plays an important role on the aggregate formation of the bolaamphiphiles ${ }^{[4,15-16}$. However, compared with the numer- ous studies on effects of head group structures, the reports on the hydrophobic chain effects are relatively rare.

On the other hand, cinnamic acid and its derivatives have been the subject of classical topochemistry for their four-centertype $2+2$ photocyclodimerization in crystalline state and other organized assemblies ${ }^{[17-20]}$. Usually, photoreaction can not take place for single chain cinnamic acid derivatives in homogeneous solution. Tanaka et al. ${ }^{[2]}$ investigated the photoreaction of OCA (4-octadecanoxycinnamic acid) in chloroform and only the cisisomer was obtained. The fact that dimerization of single chain

Received: September 22, 2005; Revised: October 25, 2005. $\quad$ *Correspondent, E-mail:jbhuang@pku. edu. cn; Tel: 010-62753557.

国家自然科学基金 $(20233010,20373003,20425310)$, 教育部博士点资助项目

C. Editorial office of Acta Physico-Chimica Sinica 
cinnamic acid derivatives does not occur in organic solutions has greatly restricted the application of these compounds in organic systems since many important chemical reactions were carried out in organic medium.

Considering the important significance of both bolaform amphiphiles and cinnamic derivatives in the research of membrane mimetic chemistry, we synthesized a new kind of bolaamphiphiles containing cinnamyl group (HDC, Scheme 1) and studied its photodimerization in organic solution and its aggregation behavior in ethanol/water suspensions. It is the first report that the single-chained HDC amphiphilic molecules dimerized in some organic solutions. The dielectric constants of the organic solvents are closely related with the photodimerization reaction. In addition, different from monomers, the dimerized HDC molecules can self-assemble into globular vesicles, which clearly displayed the influence of hydrophobic chain on the aggregation behavior.

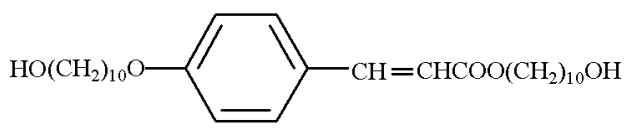

Scheme 1 Structure of HDC

\section{Experimental section}

\subsection{Synthesis of HDC}

HDC was synthesized according to the following procedure: Firstly, 1-bromo-10-hydroxyldecane was prepared from the corresponding diol and hydrobromic acid ${ }^{[22]}$ (Beijing Chemical Co., A.R.). Then a mixture of 4-hydroxyl cinnamic acid (Sigma Co., $1.64 \mathrm{~g}, 0.01 \mathrm{~mol}), 1$-bromo-10-hydroxyldecane (2.40 g, $0.01 \mathrm{~mol})$ and $7 \mathrm{~cm}^{3}$ potassium hydroxide $(1.12 \mathrm{~g}, 0.02 \mathrm{~mol})$ aqueous solution in $100 \mathrm{~cm}^{3}$ of acetone was refluxed for $72 \mathrm{~h}$. The reaction mixture was acidized with $3 \mathrm{~mol} \cdot \mathrm{dm}^{-3} \mathrm{HCl}$ and then poured into a large amount of distilled water. White solid was obtained after the solution being cooled. The solid was further purified by recrystallization three times from acetone. m.p.: 83 $85{ }^{\circ} \mathrm{C} .{ }^{1} \mathrm{H}$ NMR (200 MHz, $\mathrm{CDCl}_{3}$, TMS): $\delta: 7.6$ (1H, d, $\mathrm{Ph}-$ $\underline{\mathrm{CH}}=\mathrm{CH}-), 7.4(2 \mathrm{H}, \mathrm{d}, \underline{\mathrm{Ph}}-\mathrm{CH}=\mathrm{CH}), 6.9(2 \mathrm{H}, \mathrm{d}, \underline{\mathrm{Ph}}-\mathrm{O}), 6.3$ $(1 \mathrm{H}, \mathrm{d}, \mathrm{Ph}-\mathrm{CH}=\underline{\mathrm{CH}}), 4.2\left(2 \mathrm{H}, \mathrm{t},-\mathrm{CH}_{2} \mathrm{COO}\right), 4.0\left(2 \mathrm{H}, \mathrm{t}, \underline{\mathrm{CH}_{2}}-\right.$ $\mathrm{O}-\mathrm{Ph}), 3.6\left(4 \mathrm{H}, \mathrm{t}, \mathrm{CH}_{2}-\mathrm{OH}\right), 2.1 \quad(2 \mathrm{H}, \mathrm{t}, \mathrm{OH}), 1.3 \sim 1.7(32 \mathrm{H}$, m, $\mathrm{CH}_{2}$ ). Anal: Calcd for $\mathrm{C}_{29} \mathrm{H}_{48} \mathrm{O}_{5}: \mathrm{C}, 73.11 ; \mathrm{H}, 10.08 ; \mathrm{O}$, 16.81. Found: C, 72.93; H, 10.08 .

\subsection{Methods}

The cast films were prepared by spreading a few drops of samples on $\mathrm{CaF}_{2}$ for FT-IR and slowly drying in atmosphere at room temperature. FT-IR spectra were recorded on a Nicolet Magna-IR 750 Fourier transform spectrometer operating at 4 $\mathrm{cm}^{-1}$ resolution. The photodimerization process of HDC in chloroform and other organic solvents was carried out by irradiation using $254 \mathrm{~nm}$ UV light in quartz cell. The distance between the irradiation source and the sample was kept at $5 \mathrm{~cm}$. Absorbance changes accompanying photodimerization of HDC were tracked with a Shimadzu UV-250.

The suspensions of HDC before UV irradiation were obtained by directly sonicating $0.9 \mathrm{mg} \cdot \mathrm{dm}^{-3} \mathrm{HDC}$ in $20 \%$ ethanol/ water $(V / V)$. The dimerized HDC suspensions were prepared by evaporating the solvent from the $\mathrm{UV}$ irradiated $\mathrm{CHCl}_{3}$ solution of HDC, then re-dispersing the solids into the $20 \%$ ethanol/water mixed solvents.

Replica for TEM observation was prepared by Freeze-fracture method with a JEE- $4 \mathrm{X}$ vacuum evaporator. The vacuum is less than $1.33 \times 10^{-3} \mathrm{~Pa}$, specimen temperature: $-100{ }^{\circ} \mathrm{C} \sim-110$ ${ }^{\circ} \mathrm{C}$. TEM observation was conducted on a JEM-100 CX(II) electron microscope.

\section{Results and Discussion}

In previous literatures, usually single-chain cinnamic acid derivatives were thought not to undergo photodimerization in organic solvents ${ }^{[21]}$. However, we found that bolaamphiphile $\mathrm{HDC}$ can be photodimerized in $\mathrm{CHCl}_{3}$, as revealed both by FTIR(Fig.1) and UV (Fig.2) measurements.

The $\mathrm{CHCl}_{3}$ solution of HDC is clear and homogeneous. After irradiation, the characteristic IR absorption bands of the monomer at $977 \mathrm{~cm}^{-1}(\mathrm{CH}$-deformation mode of trans-alkenes) and $1639 \mathrm{~cm}^{-1}(\mathrm{C}=\mathrm{C}$ stretching mode $)$ disappeared. In addition, the absorption at $1707 \mathrm{~cm}^{-1}$ (CO-conjugated stretching mode) was replaced by a band at $1743 \mathrm{~cm}^{-1}$. The new formed band corresponds to the isolated $\mathrm{C}=\mathrm{O}$ stretching mode of the ester group. In agreement, the UV absorbance at the maximum of the monomeric HDC $(310 \mathrm{~nm})$ decreased with irradiation time. We further examined the ${ }^{1} \mathrm{H}$ NMR spectrum of the dimerized HDC and it was shown in Fig.3. It can be seen from Fig.3 that after 16 h UV irradiation, the characteristic $\mathrm{C}=\mathrm{C}-\mathrm{H}$ at 7.6 and 6.4 disappeared, which also indicated the occurrence of photodimeriza-

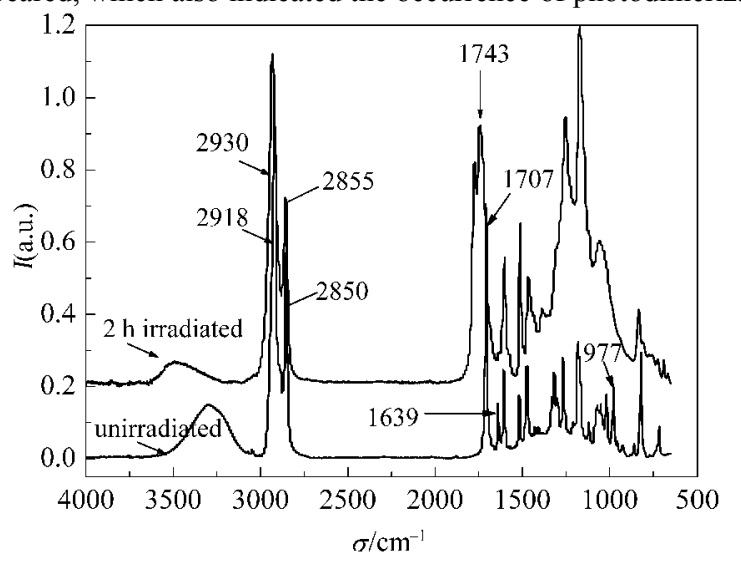

Fig.1 FT-IR Spectral changes induced by UV-irradiation for HDC in chloroform 


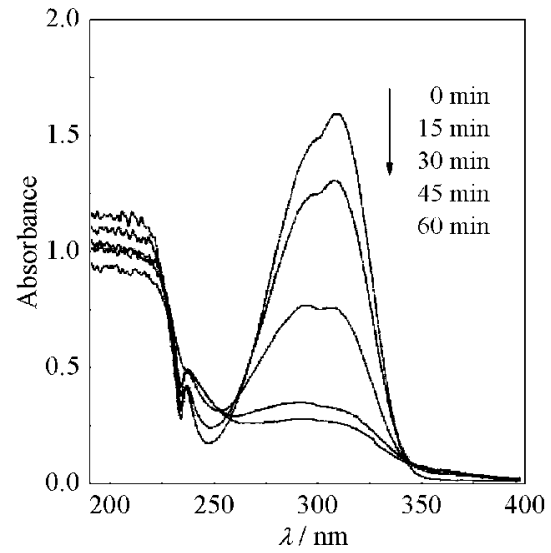

Fig.2 UV Spectral changes induced by UV irradiation for HDC in chloroform

tion of $\mathrm{HDC}$ in $\mathrm{CHCl}_{3}$. This result indicated that $\mathrm{H}$-aggregates of HDC were formed in $\mathrm{CHCl}_{3}$, which is totally different from the previous researches that single chain cinnamic acid derivatives can not dimerize in $\mathrm{CHCl}_{3}$ solutions.

In addition, the aggregation capability is also obviously changed after photo-induced process. HDC is insoluble in water while suspension can be formed for HDC in 5\% 30\% (V/V) ethanol/water mixed solvents. Before UV irradiation, no aggregates were found by TEM in the $20 \%$ ethanol/water dispersions of HDC. However, after the solvent being evaporated from the
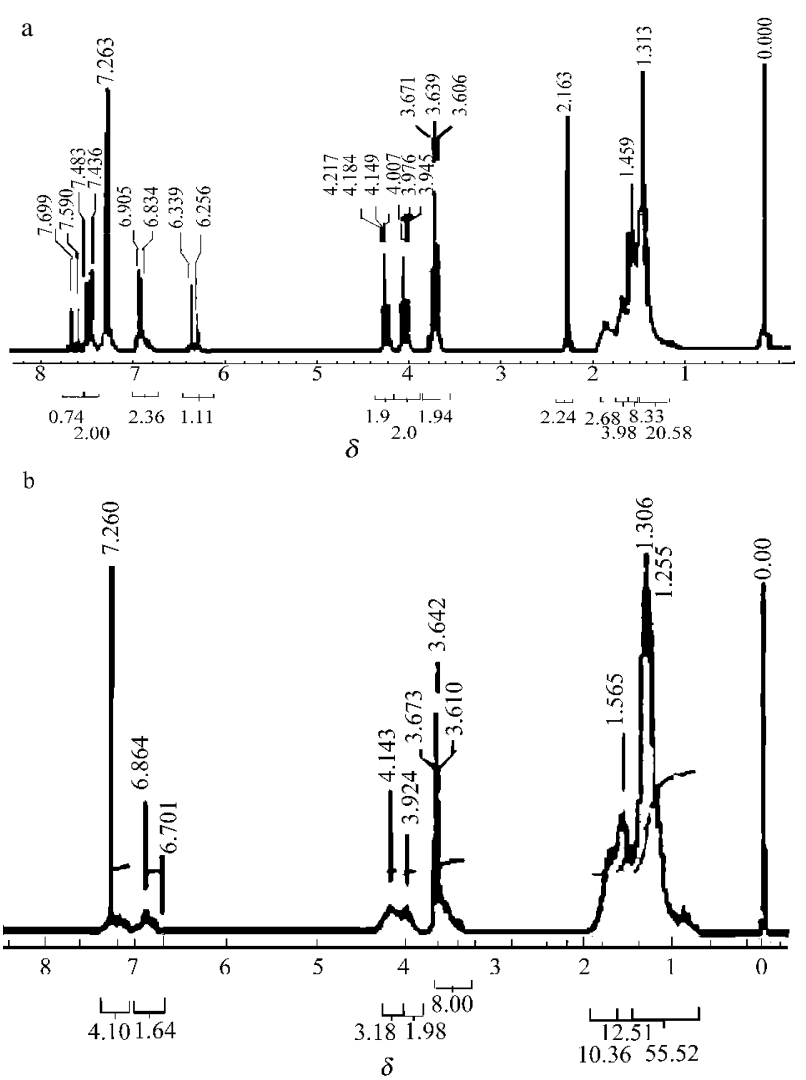

Fig.3 ${ }^{1}$ HNMR spectra of HDC before (a) and after $16 \mathrm{~h}$ UV irradiation (b)

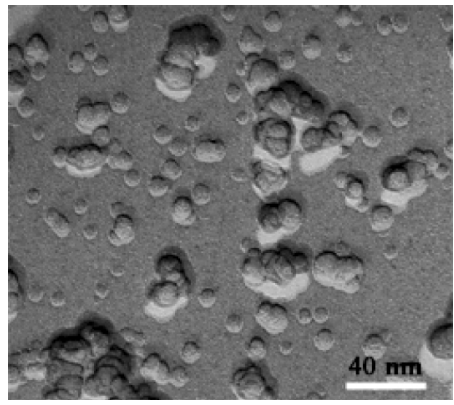

Fig.4 TEM image of the dimerized HDC in $20 \%$ ethanol/ water $(\boldsymbol{V} / \boldsymbol{V})$ suspension

irradiated $\mathrm{HDC} / \mathrm{CHCl}_{3}$ solution, the solute was redispersed into $20 \%$ ethanol/water mixed solvents and vesicles with radius of $5 \sim 15 \mathrm{~nm}$ were clearly seen (Fig.4), demonstrating that the photodimerized molecules have stronger vesicle-forming ability. This may be attributed to the formation of double chain structure of the photodimerized HDC molecules, since the double chain structure of amphiphiles is in favor of the formation of different sorts of aggregates ${ }^{[7,15]}$. As mentioned in the previous text, the former references have reported that single chain cinnamic acid derivatives cannot photodimerize in organic solvents while double chain or polymer cinnamic acid derivatives (with cinnamic acid groups in each chain) will dimerize upon UV irradiation, owing to the high local concentration of the reactive moieties within these molecules ${ }^{[23-24]}$.

It is well known that the orderly packing of the reactive center is the key factor for the occurrence of photodimerization of cinnamic acid derivatives ${ }^{[23-24]}$. From Fig.1, we can find that the symmetric and asymmetric vibration appeared at 2850 and 2918 $\mathrm{cm}^{-1}$ respectively, indicating the ordered zigzag stacking of methylene group of HDC molecules ${ }^{[25-27]}$. Thus the orderly packing of hydrocarbon skeleton of HDC makes the photo-reactive centers close to each other, and leads to the occurrence of photodimerization of HDC in chloroform. It is notable that after irradiation the $\mathrm{CH}_{2}$ asymmetric and symmetric vibronic peaks moved to 2930 and $2855 \mathrm{~cm}^{-1}$ respectively, which is corresponding to the disordered state of the hydrocarbon chains ${ }^{[25-27]}$. The wavenumber variation may be accredited to the following factors: 1) the ring tension of the newly formed four-center ring is so strong that the ring will be deformed; 2) the hydrocarbon chains from different molecules will adopt preferential conformation around the four-center ring. The above factors will make the former orderly packing of HDC molecules (before UV irradiation) impossible(See scheme 2).

HDC photodimerization reaction experiments were also performed in other organic solvents. It is notable that the UV absorbance of HDC in tetrahydrofuran, ethyl acetate and carbon tetrachloride also decreased with irradiation time (Fig.5). In contrast, UV spectra in acetone, isopropanol and $n$-butanol did not 
<smiles>[R]OC=Cc1ccc([R])c(C=CC(=O)O[R])c1</smiles>

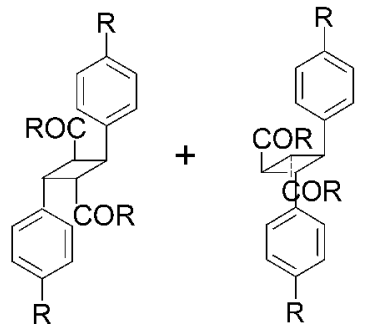

Scheme 2 Dimerization of HDC

change upon irradiation. The IR spectra also showed similar results. In Fig.6, it is clear that upon $2 \mathrm{~h}$ irradiation, the characteristic monomeric bands of HDC in tetrahydrofuran, ethyl acetate disappeared, but that in isopropanol kept unchanged. The experimental results about the photoreaction of HDC in organic solvents after UV irradiation were shown in Table 1.

It was worth to note that the photoreaction of HDC occurred in solvents with smaller values of dielectric constants; on the contrary, no dimerization was found in solvents with larger values of dielectric constants. This indicates that strong interaction existed between molecules and the solvents with higher dielectric constants, which leads to the HDC molecules separated and the photodimerization then forbidden. On the contrary, weaker interaction between molecules and solvents with lower dielectric constants made the close packing of two cinnamyl reactive centers possible, which causes the occurrence of dimerization in the organic solution.

It is also found that the dielectric constant values of the sol-
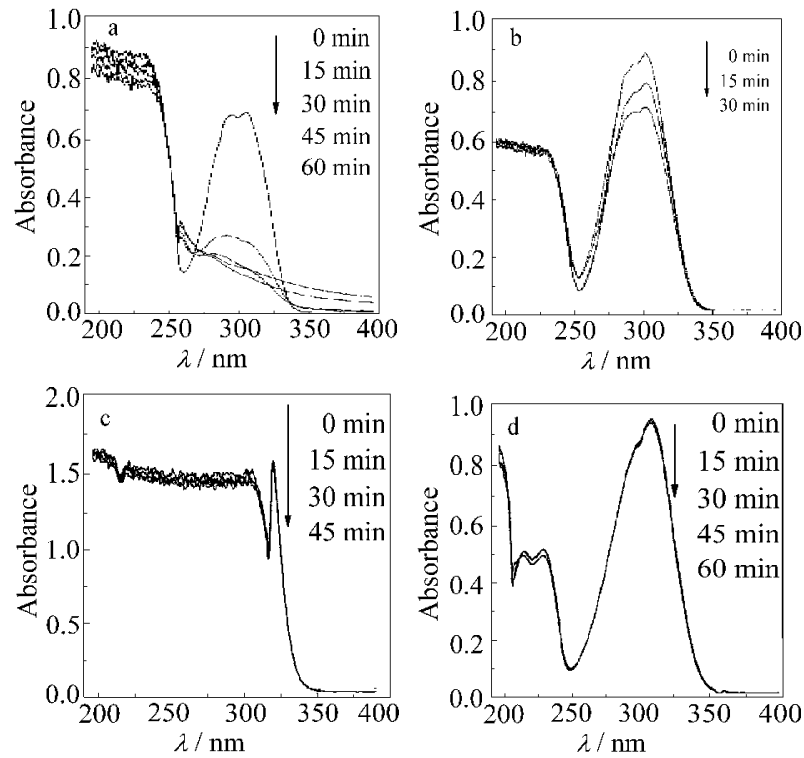

Fig.5 UV Spectra of HDC in different organic solvents under UV irradiation

The digital numbers beside the arrow represent the UV irradiation time. a) in carbon tetrochloride; b) in ethyl acetate; c) in acetone; d) in $n$-butanol. It was seen that the absorbance decreased apparently in a) and b) while they kept stable in c) and d).

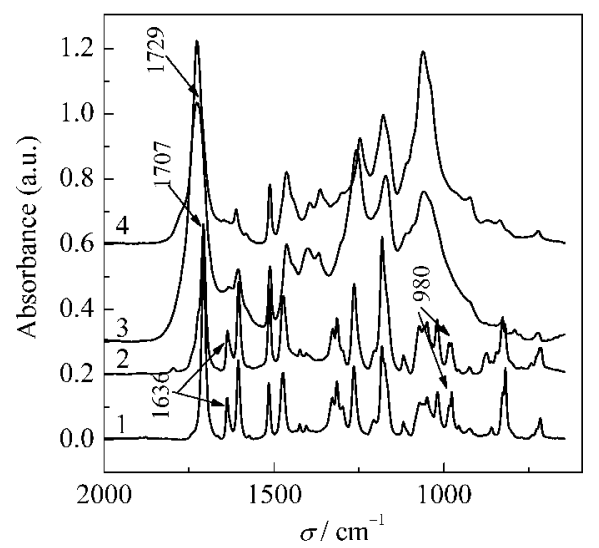

Fig.6 IR spectra of HDC in different organic solvents after UV irradiation

1) dichloromethane; 2) isopropanol; 3) ethyl acetate;

4) tetrahydrofuran

Table 1 The photoreaction of HDC in organic solvents with different dielectric constants

\begin{tabular}{ccc}
\hline Solvent & Dielectric constants $^{*}$ & Reaction \\
\hline Acetone & 20.7 & - \\
Isopropanol & 18.3 & - \\
$n$-Butanol & 17.5 & - \\
Dichloromethane & 9.08 & - \\
Tetrahydrofuran & 7.58 & + \\
Ethyl acetate & 6.02 & + \\
Chloroform & 4.81 & + \\
Carbon tetrachloride & 2.24 & + \\
\hline -: no photoreaction occurred; +: photoreaction was observed &
\end{tabular}

vents also influence the rate of the photo reaction in these systems. For example, the UV absorbance of $\mathrm{HDC}$ in $\mathrm{CHCl}_{3}$ only decreased 22\% after 15 min UV irradiation(Fig.2), while the absorbance in carbon tetrachloride (Fig. 5 a) decreased $67 \%$ after the same irradiation time. Fig.7 illustrated the UV absorbance de creases of HDC in different organic solvents upon $15 \mathrm{~min}$ UV ir

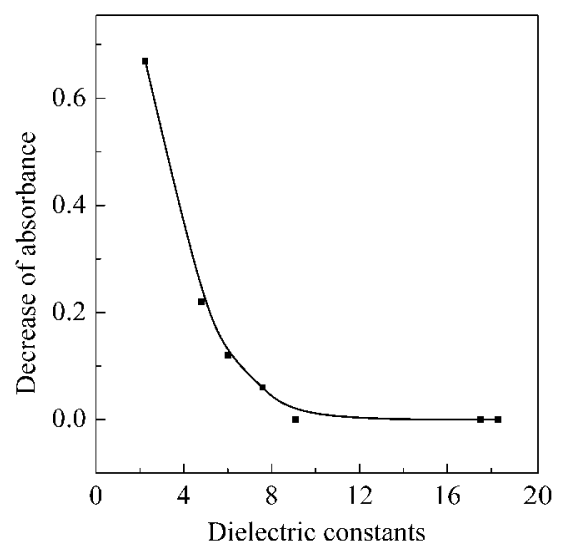

Fig.7 The relationship between the decrease of UV absorbance and the dipole moment of solvents The concentration of HDC: $6.3 \times 10^{-4} \mathrm{~mol} \cdot \mathrm{dm}^{-3}$ 
radiation. It is clearly shown that the photoreaction in organic solvents will be faster with the decrease of the dielectric constants of the solvents when the dielectric constants of the solvents are smaller than 9.0. This result indicates that the interaction between solvent and solute molecules is a key factor to the photoreaction in the cinnamic acid derivative systems. It is valuable in expanding the photodimerizing reaction of cinnamic acid derivatives to the organic systems.

\section{Conclusion}

A new single chain photoreactive bolaamphiphile HDC containing cinnamic group was synthesized. UV and IR spectra revealed that the single chain HDC molecules dimerized in chloroform, carbon tetrachloride, ethyl acetate and tetrahydrofuran, while not in some other organic solvents, such as acetone, isopropanol et al. The photodimerization was closely related with dielectric constants of solvents. The dimerized HDC self-organized into globular vesicles in the $20 \%$ ethanol/water $(V / V)$ suspensions. This may be attributed to that the double chain structure of the photodimerized product is in favor of molecular selfassembly.

\section{References}

1 Meguro, K.; Ikeda, K.; Otsuji, A.; Yaya, M.; Yasuda, M.; Esumi, K. J. Colloid Interface Sci., 1987, 118: 372

2 Mackenzie, K. C.; Bunton, C. A.; Nicoli, D. F.; Savelli, G. J. Phys. Chem., 1987, 91: 5709

3 Clary, L.; Gadras, C.; Greiner, J.; Rolland, J. P.; Santaella, C.; Vierling, P.; Gulik, A. Chemistry and Physics of Lipids, 1999, 99: 125

4 Fuhrhop, J. H.; Spiroski, D.; Boettcher, C. J. Am. Chem. Soc., 1993, 115: 1600

5 Franceschi, S.; de Viguerie, N.; Riviere, M.; Lattes, A. New J. Chem., 1999, 23: 447

6 Yan, Y.; Huang, J. B.; Li, Z. C.; Han, F.; Ma, J. M. Langmuir, 2003, 19: 972

7 Okahata, Y.; Kunitake, T. J. Am. Chem. Soc., 1979, 101: 5231
8 Yan, Y.; Xiong, W.; Huang, J. B.; Li, Z. C.; Li, X. S.; Li, N. N.; Fu, H. L. J. Phys. Chem. B, 2005, 109:357

9 Fuhrhop, J. H.; Mathieu, J. J. Chem. Soc., Chem. Commun., 1983: 144

10 Wang, K. S.; Munoz, S.; Zhang, L. T.; Castro, R.; Kaifer, A. E.; Gokel, G. W. J. Am. Chem. Soc., 1996, 118: 6707

11 Liang, K. N.; Hui, Y. Z. J. Am. Chem. Soc., 1992, 114: 6588

12 Visscher, I.; Engberts, J. B. F. N. Langmuir, 2000, 16: 52

13 Meglio, C. D.; Rananavare, S. B.; Svenson, S.; Thompson, D. H. Langmuir, 2000, 16: 128

14 Munoz, S.; Mallen, J.; Nakano, A.; Chen, Z. H.; Gay, I.; Echegoyen, L.; Gokel, G. W. J. Am. Chem. Soc., 1993, 115: 1705

15 Fuhrhop, J. H.; David, H. H.; Mathieu, J.; Liman, U.; Winter, H. J.; Boekema, E. J. Am. Chem. Soc., 1986, 108: 1785

16 Fuhrhop, J. H.; Fritsch, D.; Tesche, B.; Schmiady, H. J. Am. Chem. Soc., 1984, 106: 1998

17 Koch, H.; Laschewsky, A.; Ringsdorf, H.; Teng, K. Makromol. Chem.-Macromol. Chem. Phys., 1986, 187: 1843

18 Xia, Q.; Feng, X. S.; Mu, J.; Yang. K. Z. Langmuir, 1998, 14: 3333

19 Kawatsuki, N.; Takatani, D.; Yamamoto, T.; Ono, H. Polymer Journal, 1998, 30: 946

20 Yamamoto, M.; Furuyama, N.; Itoh, K. J. Phys. Chem., 1996, 100: 18483

21 Tanaka, Y.; Nakayama, K.; Iijima, S.; Shimizu, T.; Maitani, Y. Thin Solid Film, 1985, 133: 165

22 Chong, J. M.; Heuft, M. A.; Rabbat, P. J. Org. Chem., 2000, 65: 5837

23 Tian, Y. C. J. Phys. Chem., 1991, 95: 9985

24 Tieke, B.; Enkelmann, V.; Kapp, H.; Lieser, G.; Wegner, G. J. Macromol. Sci. -Chem., 1981, A15 (5): 1045

25 Sapper, H.; Cameron, D. G.; Mantsch, H. H. Can. J. Chem., 1981, 59: 2543

26 Yan, Y.; Huang, J. B.; Li, Z. C.; Han, F.; Ma, J. M.; Fu, H. L.; Ye, J. P. J. Phys. Chem. B, 2003, 107: 1479

27 Nakagoshi, A.; Terashtia, S. I.; Ozaki, Y.; Iriyama, K. Langmuir, 1994, 10: 779

28 Dean, J. A. Lange's handbook of chemistry. 13th ed. New York, London: McGraw-Hill, 1985 